\title{
Palaeobotanical redux: revisiting the age of the angiosperms
}

\author{
Patrick S. Herendeen ${ }^{1 \star}$, Else Marie Friis ${ }^{2}$, Kaj Raunsgaard Pedersen ${ }^{3}$ and Peter R. Crane ${ }^{4,5}$
}

Angiosperms (flowering plants) are the most diverse of all major lineages of land plants and the dominant autotrophs in most terrestrial ecosystems. Their evolutionary and ecological appearance is therefore of considerable interest and has significant implications for understanding patterns of diversification in other lineages, including insects and other animals. More than half a century ago, influential reviews showed that while angiosperms are richly represented in sediments of Late Cretaceous and younger ages, there are no reliable records of angiosperms from pre-Cretaceous rocks. The extensive new macrofossil, mesofossil, and microfossil data that have accumulated since have confirmed and reinforced this pattern. Recently, however, molecular dating methods have raised the possibility that angiosperms may have existed much earlier, and there have been scattered reports of putative angiosperms from Triassic and Jurassic rocks. Critical assessment of these reports shows that, so far, none provide unequivocal evidence of pre-Cretaceous angiosperms. Angiosperms may ultimately be recognized from Jurassic or earlier rocks, but credible palaeobotanical evidence will require unambiguous documentation of the diagnostic structural features that separate angiosperms from other groups of extant and extinct seed plants.

M ore than half a century ago, two pivotal reviews ${ }^{1,2}$ showed that while the fossil history of angiosperms "is extraordinarily and increasingly well documented in post-Early Cretaceous sediments...no bona fide angiosperm remains, either megafossil or microfossil, have yet been described from rocks older than Early Cretaceous"1. Here, we revisit this conclusion and assess the extent to which the situation has changed, given a substantial increase in the quantity and quality of palaeobotanical data and an increasing number of reports of angiosperms from older rocks.

Since the key reviews of the 1960s, great progress has been made in understanding the major patterns in the angiosperm fossil record ${ }^{3-5}$. There have also been significant advances in understanding evolutionary relationships within the angiosperm clade-especially in using DNA sequences from living plants to reconstruct phylogenetic patterns ${ }^{6}$. Widely accepted hypotheses indicate that more than $99 \%$ of angiosperm species occur in three major clades (eudicots, monocots, (eu)magnoliids), which are embedded in a paraphyletic assemblage of other early diverging lineages that includes Amborellales, Austrobaileyales, Ceratophyllales, Chloranthales and Nymphaeales ${ }^{6-8}$. More controversial are estimates of the age of the most recent common ancestor of extant angiosperms based on molecular clock techniques, and hypotheses of the phylogenetic position of angiosperms in relation to other seed plant lineages. As molecular clock estimates are most often calibrated using palaeontological data, and because the closest relatives to angiosperms are almost certainly extinct groups, fossils are integral to progress in both of these areas.

Building on important advances made during the $1970 \mathrm{~s}^{3,4,9}$, recent decades have seen an explosion of new systematically informative data on early angiosperms, including discoveries of abundant three-dimensionally preserved flowers and other reproductive structures in the Early and Late Cretaceous (see references in ref. 10). There have also been important reports of flowers preserved as compressions or impressions from Early Cretaceous strata $^{11-13}$. Taken together, these discoveries and their sequence of appearance in the fossil record are broadly consistent with the patterns of relationships established among extant angiosperms using molecular data, and the associated patterns of character evolution. All of the reproductive structures recognized so far from Early Cretaceous sediments are either extinct forms, apparently with no close relatives among living angiosperms, or are related to Austrobaileyales, Chloranthales, Nymphaeales, various groups of eumagnoliids, or early branches of eudicots or monocots (Fig. 1, for references see refs 10 and 14). Preservation of fine structural details in some of these Early Cretaceous fossils further confirms their inferred relationship with extant lineages that are hypothesized to have diverged at an early stage in angiosperm diversification based on molecular phylogenetics ${ }^{15}$.

The improved angiosperm fossil record from the Cretaceous has facilitated the calibration of molecular clock age estimates for various angiosperm clades and for the age of angiosperms as a whole $\mathrm{e}^{16-21}$. While current techniques remain susceptible to problems resulting from significantly different rates of molecular evolution and levels of diversification among different angiosperm clades, as well as taxon-sampling strategies ${ }^{18,20}$, results from some such studies suggest ages for the angiosperm crown group that are considerably older than those indicated by most assessments of the palaeobotanical record ${ }^{21-24}$. This provides a context in which claims of pre-Cretaceous angiosperms take on particular importance.

It is also significant that even though phylogenetic relationships among angiosperms and other seed plants remain uncertain, the other four groups of living seed plants (cycads, conifers, Ginkgo, Gnetales), as well as potentially relevant extinct clades (for example, Bennettitales, Caytoniales, Corystospermales), have fossil histories that extend back to the Triassic or earlier. This implies that the angiosperm stem-lineage had diverged from those of other seed

\footnotetext{
'Chicago Botanic Garden, 1000 Lake Cook Road, Glencoe, Illinois 60022, USA. ²Department of Palaeobiology, Swedish Museum of Natural History, SE-104 05 Stockholm, Sweden. ${ }^{3}$ Department of Earth Science, University of Aarhus, DK-8000 Aarhus, Denmark. ${ }^{4}$ Oak Spring Garden Foundation, 1776 Loughborough Lane, Upperville, Virginia 20184, USA. ${ }^{5}$ Yale School of Forestry and Environmental Studies, 195 Prospect Street, New Haven, Connecticut 06511, USA. *e-mail: pherendeen@chicagobotanic.org
} 
plants by at least the Late Triassic, or perhaps earlier. It is therefore possible that crown-group angiosperms existed before the Early Cretaceous and it is likely that some seed plants from the Triassic and Jurassic possessed some, but not all, of the features of crowngroup angiosperms, defined as the most recent common ancestors of all living angiosperms and its derivatives ${ }^{25,26}$.

\section{Recognizing early angiosperms in the fossil record}

The ability to infer the presence of the angiosperm crown group from incomplete fossil evidence is fundamental to discussions of the age of angiosperms as the fossil record mainly comprises only fragments of extinct plants. Only some of the key features (synapomorphies $)^{10,27}$ that are restricted to the angiosperm crown group

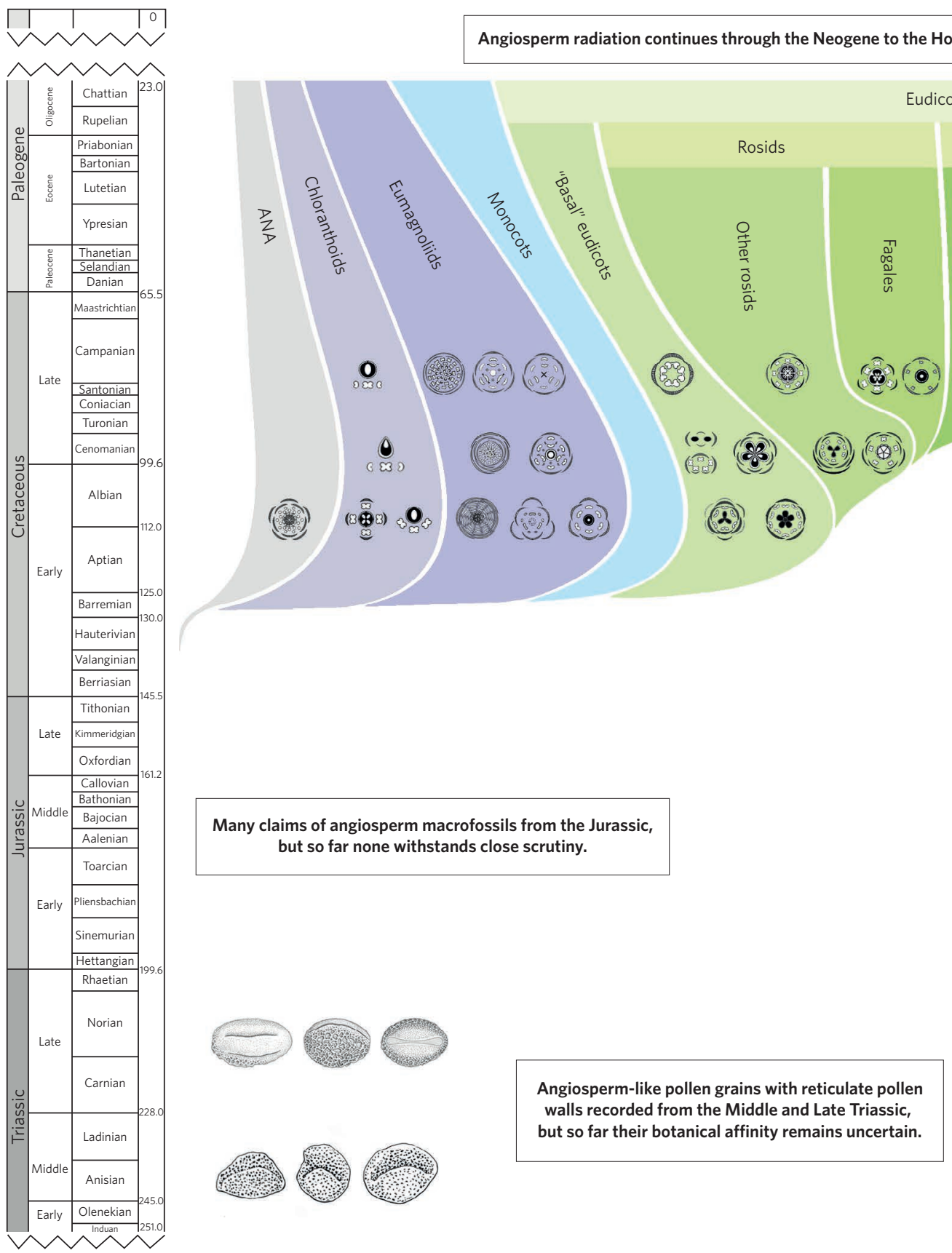

Figure 1 | Fossil ranges of major angiosperm lineages, focused on the Cretaceous diversification. The fossil record of plant micro-, meso- and macrofossils shows that the first major radiation of angiosperms took place in the Early Cretaceous. Fossil flowers recognized so far from the Early Cretaceous are either extinct forms, apparently with no close relatives among living angiosperms, or are related to Austrobaileyales, Chloranthales, Nymphaeales, various groups of eumagnoliids, or early branches of eudicots or monocots. Floral diagrams of Early Cretaceous angiosperms from left to right: ANA: Monetianthus (Nymphaeales); chloranthoids: Canrightia and Canrightiopsis; eumagnoliids: Virginianthus, Powhatania and Potomacanthus (Laurales); basal eudicots: Kajanthus (Ranunculales) and Kenilanthus (uncertain position). Floral diagrams of mid-Cretaceous angiosperms from left to right: chloranthoid: unnamed Chloranthistemon-like flower; eumagnoliids: Archaeanthus (Magnoliales) and Mauldinia (Laurales); basal eudicots: Spanomera (Buxales) and Friisicarpus (Proteales); rosids: Caliciflora and unnamed Rose Creek rosid (precise placement among Pentapentalae uncertain). Floral diagrams of Late Cretaceous angiosperms from left to right: chloranthoids: Chloranthistemon; eumagnoliids: Futabanthus (Magnoliales), Neusenia and Lauranthus (Laurales); basal eudicots: Quadriplatanus (Proteales); rosids: Platydiscus (Oxidales), Archaefagacea and Manningia (Fagales); asterids: Paradinandra and Parasaurauia (Ericales), Silvianthemum and Bertilanthus (Paracryphiales). ANA, Amborellales-Nymphaeales-Austrobaileyales. 
are likely to be preserved in fossil material (for example, morphological features of flowers or pollen grains), whereas others are very unlikely to be preserved (for example, formation of an endosperm). In addition, aggregation of ovulate and/or pollen-producing organs into a structure surrounded by sterile parts (that is, a 'flower') is not, by itself, a reliable criterion for recognizing a fossil as an angiosperm. Aggregations of the structures bearing ovules or pollen sacs are very common among seed plants, and flower-like reproductive structures occur in several groups of non-angiosperm seed plants (for example, Bennettitales, Gnetales). Also, in some angiosperms, including several lineages near the base of the angiosperm phylogeny (for example, Hydatellaceae and certain Chloranthaceae), a discrete flower is difficult to define ${ }^{28}$.

In theory, plant fossils that can be assigned convincingly to a clade of extant angiosperms, or to the stem group of such a clade, are unproblematic. They provide a minimum age for the clade to which they are assigned and they can be inferred with high confidence to have possessed all of the diagnostic features of the angiosperm crown group. Examples of such fossils from the Early and mid-Cretaceous include Monetianthus (Nymphaeales) ${ }^{29}$, Canrightiopsis (Chloranthaceae) $)^{30}$, Archaeanthus (Magnoliaceae) ${ }^{31}$, Mauldinia (Lauraceae) ${ }^{32}$, Kajanthus (Ranunculales) ${ }^{33}$ and numerous others ${ }^{10}$. However, in many cases, even in otherwise highly informative fossil material, the essential features of a specific extant clade of angiosperms are not preserved. In such situations, there cannot be certainty that all the diagnostic features of crown-group angiosperms were present in the fossil taxon. Uncertainty about the precise topology at the base of the angiosperm phylogeny, and therefore the optimization of key characters, as well as extensive homoplasy, creates further difficulties. Therefore, while it is reasonable to infer a phylogenetic position among crown-group angiosperms for isolated fossil organs that show unique angiosperm features (for example, tetrasporangiate dithecate stamens with four pollen sacs arranged in two pairs, pollen grains with multiple apertures in a radially symmetrical or global arrangement, and carpels enclosing one or several bitegmic ovules with two integuments; Fig. 2), incomplete information about the other parts of such fossil plants limits the conclusions that can be made. As a result, the possibility that such fossils were actually on the angiosperm stem group rather than in the crown group cannot be completely excluded. The uncertainty over the phylogenetic position of Archaefructus provides a case in point ${ }^{12,34,35}$. The situation is especially complex for isolated angiosperm-like pollen grains with a single distal aperture (monocolpate), where there may be very few diagnostic angiosperm features (columellate pollen wall, endexine either absent or lacking prominent lamellae). In such cases, significant progress will only come when these pollen grains are found in the organs that produced them, or when they can be linked convincingly to a specific ovulate reproductive structure.

\section{Evidence from fossil pollen}

Earlier reviews ${ }^{1,2}$ highlight data from fossil pollen as especially important for assessing the age of angiosperms because they overcome some limitations of the fossil record of leaves and other larger structures (macrofossils). Pollen grains are more widely dispersed, occur in greater quantities, and have higher preservation potential in a wider range of sediments than other kinds of plant fossils. They can also provide evidence of vegetation growing away from those depositional environments in which other kinds of plant fossils are most frequently preserved.

Since the 1960s, there has been a massive increase in the availability of fossil pollen data. These data have been collected from all over the world for a variety of purposes, including exploration geology, from strata of Late Devonian age through to the present. These data, comprising thousands of samples and millions of individual pollen records, have so far failed to document unequivocal angiosperm pollen prior to the Early Cretaceous ${ }^{5,10,36}$.
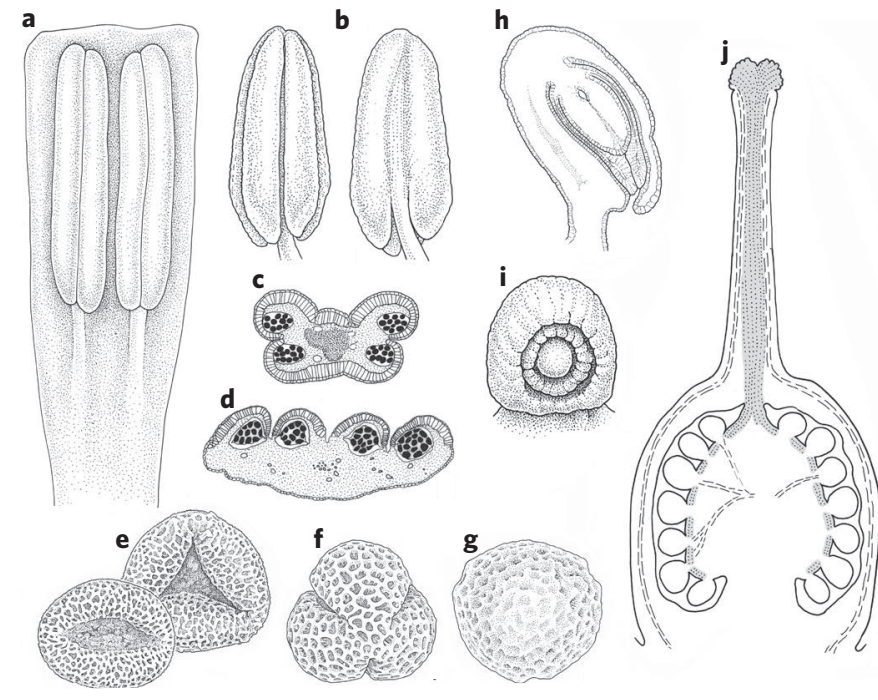

Figure 2 | Illustrations of angiosperm reproductive structures to show derived diagnostic features that characterize flowering plants. a-d, Tetrasporangiate anthers with two pairs of pollen sacs. a, Laminar stamen showing four pollen sacs in two pairs and no differentiation between filament and anther. $\mathbf{b}$, Tetrasporangiate stamen with welldifferentiated anther and filament. c, Transverse section of anther shown in $\mathbf{b}$ to show four pollen sacs. $\mathbf{d}$, Transverse section of $\mathbf{a}$ to show four pollen sacs. e-g, Pollen grains. e, Monocolpate and trichotomocolpate apertures. $\mathbf{f}$, Tricolpate aperture configuration. $\mathbf{g}$, Triporate aperture configuration. $\mathbf{h}, \mathbf{i}$, Bitegmic ovules; $\mathbf{h}$ shows longitudinal section of ovule showing two enclosing integuments, while $\mathbf{i}$ shows a view of micropyle showing two integuments. j, Carpel composed of well-differentiated ovary, style and stigma with ovules enclosed within the ovary. Adapted from ref. 10, Cambridge University Press.

Detailed studies of palynological sequences from the Early Cretaceous using scanning electron microscopy also demonstrate that angiosperm-like pollen is extremely rare in pre-Barremian strata ${ }^{5,36-41}$ and that samples from the earliest Early Cretaceous (Berriasian) are devoid of pollen grains that can be assigned plausibly to angiosperms. All of the angiosperm-like pollen grains reported from the Valanginian-Hauterivian are monocolpate (also called monosulcate) or a similar form. None are triaperturate (tricolpate, tricolporate or triporate), with the three germinal apertures equally distributed around the equator of the grain. This kind of triaperturate grain is especially significant as except for partial convergence in Schizandraceae, it is known only in the eudicots, the clade that contains more than $70 \%$ of all living angiosperm species. It thus provides evidence to recognize crown-group angiosperms with very high confidence. Triaperturate grains are first recorded around the Barremian-Aptian boundary ${ }^{36}$ and as they are easy to recognize, if present in pre-Barremian-Aptian sediments, they would certainly have been identified, even in routine palynological studies using light microscopy ${ }^{10,42}$. The absence of triaperturate grains in older rocks is negative evidence, but the pattern is nonetheless conspicuous and compelling.

The occurrence of eudicot-type triaperturate pollen at an early stage in the angiosperm fossil record, but only after the first appearance of the earliest monocolpate angiosperm grains, is consistent with predictions of character state evolution based on phylogenetic studies of living plants, and by the end of the Early Cretaceous, triaperturate pollen grains were diverse, and sometimes abundant $t^{4,10}$. Other multiaperturate pollen types, such as pantoporate pollen (for example, Cretacaeiporites) are also unique to angiosperms and are first recorded from around the early Aptian ${ }^{43}$.

In the case of some monoaperturate angiosperm-like grains from early phases of the Early Cretaceous $5^{5,36,38-40,44}$, additional 
information has confirmed their angiosperm affinity. For example, some of these grains have been shown to be very similar to pollen of extant Chloranthaceae ${ }^{45}$, and their angiosperm affinity has also been confirmed by the discovery of similar grains in situ within pollen organs and on the stigmatic surfaces of small fruits in Early Cretaceous mesofossils $\left.{ }^{10}\right)$.

Notwithstanding the value of the fossil pollen record for interpreting the age of angiosperms, there are still significant limitations in terms of representation of the original vegetation, recognition in palynological samples, and the extent to which systematic assignment is possible $e^{46}$. The representation of regional vegetation in dispersed pollen floras is often limited, pollen of insect-pollinated plants is often not abundant or widely dispersed, and standard methods of preparing and observing palynological samples are biased against very small and very rare grains. Compared to other plant organs, the record of pollen grains has many advantages, but it is far from perfect and typically, pollen grains preserve only a few features of systematic importance.

Pollen records from Triassic rocks of angiosperm-like pollen with reticulate and sometimes obviously columellate wall structure deserve special consideration. Even though nothing is known about the other parts of the plants that produced these grains, among living seed plants pollen of this kind is known only from angiosperms and it is essential that pre-Cretaceous and younger material is evaluated on the same basis. Especially important are pollen grains of the Crinopolles group from the Late Triassic of the Richmond Rift Basin ${ }^{47}$ that have certain angiosperm-like features, and angiosperm-like grains from the Middle Triassic of the Germanic Basin, Switzerland ${ }^{48}$ and the Barents Sea, Norway ${ }^{49}$.

Although columellate pollen wall structure has been considered as unique to angiosperms, Crinopolles grains seem more likely to have been produced by non-angiospermous seed plants because of their thick, laminated endexine $\mathrm{e}^{47,50}$, which is not known among angiosperms but is characteristic for pollen of all other living seed plants. Further, multiaperturate Crinopolles-type pollen exhibits an unusual distribution of apertures similar to that seen in the grains of Eucommiidites, pollen of an extinct group of seed plants closely related to Gnetales ${ }^{10}$. The unnamed angiosperm-like grains described by Hochuli and Feist-Burkhardt ${ }^{48,49}$ may represent a similar situation, but the wall ultrastructure is unknown and details of the grains are not sufficient for a thorough systematic assessment. It may also be significant that similar reticulate angiosperm-like grains have not been reported from the Jurassic.

In considering the potential affinities of these kinds of enigmatic pollen, past experience also suggests reasons for caution. Pollen grains of Eucommiidites, which are common in Triassic, Jurassic and Cretaceous sediments, were described originally as tricolpate angiosperm grains resembling pollen of the extant angiosperm Eucommia. They are now known to have been produced by an extinct group of non-angiosperm seed plants, Erdtmanithecales ${ }^{51}$. The unusual distribution of the apertures hinted at a non-angiosperm relationship ${ }^{52}$, which was confirmed subsequently by the consistent occurrence of Eucommiidites grains in the micropyles of dispersed seeds ${ }^{53,54}$. Subsequent studies also showed that Eucommiidites-producing pollen organs differ greatly from angiosperm stamens ${ }^{51,55,56}$ and that the seeds are very similar to those of fossil and extant Gnetales ${ }^{55}$.

\section{Evidence from mesofossils and macrofossils}

Discoveries of abundant angiosperm mesofossils in Early Cretaceous sediments ${ }^{10}$ have opened a new window into the early phases of angiosperm diversification. There are now many examples of whole flowers or fragments of reproductive structures with well-preserved carpels that also show other critical features, such as the stigmatic area, sometimes with adhering pollen, and one or more enclosed ovules or seeds, sometimes clearly with two integuments and a dicotyledonous embryo (for example, Canrightiopsis ${ }^{15,30}$ ). There are also many Early Cretaceous examples of tetrasporangiate dithecate stamens, in flowers or isolated, with four pollen sacs arranged in two pairs. These fossilize easily and often have pollen grains with typical angiosperm features preserved in situ. When unequivocal carpels and stamens can be shown to come from the same fossil species, the presence of crown-group angiosperms can be inferred with reasonable confidence, even though a position on the angiosperm stem group cannot be excluded completely in some cases.

In all cases, however, careful study and interpretation is crucial for evaluating the structure of fossils that may indicate the presence of angiosperms. For example, in many fossil seeds, including those of unequivocal angiosperms, it is often hard to determine whether there are one or two integuments, and seeds enclosed in modified bracts or other structures that may resemble the angiosperm carpel are known from several non-angiospermous seed plants. The case of Caytonia is well known. Originally described as an angiosperm because the seeds are enclosed inside a fleshy fruit-like structure, it was later shown that the pollen grains had direct access to the micropyle of the enclosed seeds, a key difference between pollination in angiosperms and other seed plants. Thus, distinguishing angiosperm carpels from structures that enclose the ovules in other seed plants such as Vladimaria $a^{57}$ and Umkomasia ${ }^{58}$ is critical, as is knowledge of what the other plant parts (if known) indicate about possible relationships. In Caytonia, the pollen grains are saccate and have a non-angiospermous wall structure with a thick endexine ${ }^{59}$. However, interest in Caytonia would be revived if it were ever shown that the ovules were bitegmic, or that the four pollen sacs of the Caytonanthus pollen organ were arranged in two pairs as in angiosperm stamens.

Two ovulate structures from the Early Cretaceous illustrate the challenge of interpreting the structure of even favourably preserved fossil material. Both were first reported as trimerous and tetramerous reproductive structures with apical tepal-like organs, and both superficially resemble an epigynous angiosperm flower ${ }^{60}$. Additional material, and more detailed study using synchrotron X-ray microtomography, subsequently demonstrated that the trimerous structure was a pistillate angiosperm flower closely related to the extant genus Hedyosmum (Chloranthaceae ${ }^{10}$ ), while the four-angled ('tetramerous') structure, now named Tomcatia taylori, ${ }^{61}$ is a non-angiospermous seed with distinct chlamydospermous organization ${ }^{61,62}$. Tomcatia has tepal-like projections of the seed envelope that are not known in any living seed plant. It is part of a diverse complex of seed plants related to extant Gnetales and extinct Erdtmanithecales that were important in Early Cretaceous vegetation ${ }^{61,63,64}$

Notwithstanding these difficulties, it is important to note that while mesofossil floras with angiosperm reproductive structures are common and diverse from around the Barremian-Aptian and onwards, no angiosperms have been discovered in the mesofossil floras from the earliest part of the Cretaceous and from the Jurassic that have been investigated.

\section{Disputed claims of pre- and Early Cretaceous angiosperms} Several putative angiosperm fossils described from the Early Cretaceous are problematic for various reasons and fail to provide evidence of an angiosperm relationship. Among them, Bevhalstia, from the Early Cretaceous (latest Hauterivian to earliest Barremian) of southern England, is an intriguing potential herbaceous angiosperm $^{65}$, as is Montsechia from the Barremian of Spain ${ }^{66}$, but in both cases their relationships are unknowable based on the poorly preserved material currently available (for Bevhalstia see discussion in ref. 10). Similarly, Liaoningfructus ascidiatus, from the Early Cretaceous Yixian Formation (Barremian-Aptian) of Liaoning, China, initially interpreted as a fruit with ascidiate carpels containing two seed ${ }^{67}$, is very similar to specimens described as Archaeamphora longicervia ${ }^{68}$, which have now been reassessed as 
galls on the linear leaves of Liaoningocladus, a common putative conifer in the Yixian Formation ${ }^{69}$.

Baicarpus $^{70}$, Callianthus dilae ${ }^{71}$ and Chaoyangia liangii ${ }^{72}$, also from the Yixian Formation of Liaoning, China, have likewise been attributed to angiosperms. However, Baicarpus has been transferred to the extinct genus Prognetella Krassilov et Bugdaeva and assigned to the Ephedracea ${ }^{73,74}$, while fossils of Callianthus dilae are very similar to fossils described as Gurvanella dictyoptera ${ }^{75}$. Fossils of the Callianthus-Chaoyangia-Gurvanella complex, some of which show probable ovulate reproductive structures attached to vegetative axes, are relatively common in the Yixian Formation. Although not well enough preserved for detailed structural study, their relationships are most likely with Gnetales (for further details see ref. 10).

These Early Cretaceous fossils illustrate the difficulties of interpreting poorly preserved fossil material, but special care is warranted with older material that is critical for assessing the timing of angiosperm diversification. Excluding occasional examples where key specimens from the Cretaceous had been stratigraphically misassigned to the Jurassic (such as Archaefructus ${ }^{76}$ ), these older fossils fall into two groups: (1) intriguing fossils for which there is insufficient information to assess their affinities (for example, Sanmiguelia lewisii Brown from the Triassic of Texas, United States; Phyllites sp. from the Jurassic Stonesfield Slate, England); and (2) fossils claimed as angiosperms for which evidence of an angiosperm relationship is either weak or non-existent. Fossils of the first kind have been discussed elsewhere ${ }^{22,77}$ and so far none provide convincing evidence of pre-Cretaceous angiosperms. However, in the latter group are several fossils of Jurassic age from Inner Mongolia and Liaoning Province, China, that have been claimed as pre-Cretaceous angiosperms and that need to be assessed: Euanthus panii, Xingxueanthus sinensis and Schmeissneria from the Jiulongshan (Haifanggou) Formation at Sanjiaocheng Village, and Juraherba bodae and Yuhania daohugouensis from the Jiulongshan Formation at the Daohugou locality.

Euanthus panii ${ }^{78}$, described as a perigynous pentamerous flower, in our view is more probably a fragment of slightly disintegrated conifer cone (for example, Tsuga, Fig. 3), which is also consistent with the abundant twigs and leaves of conifers preserved in the Jiulongshan Formation. The thick, apparently woody 'perianth parts' are also more suggestive of a cone. Juraherba bodae, described as an herbaceous angiosperm with attached roots (with root hairs), stems, leaves and fruits ${ }^{79}$, appears to have leaves that are extremely thin and, in our opinion, the preservation is inadequate for critical assessment of relationships. Yuhania daohugouensis ${ }^{80}$, also interpreted as an angiosperm based on a single specimen with poor preservation, presents a similar situation. Also unconvincing are the supposed angiosperm features of Xingxueanthus sinen$s i{ }^{81}$ and species of Schmeissneria from China and Germany that have been reinterpreted as angiosperms $s^{82,83}$. Detailed study by van Konijnenburg-van $\mathrm{Cittert}^{84}$ interpreted the pollen organs and leaves linked with Schmeissneria in Germany as related to Ginkgoales.

Solaranthus daohugensis (now transferred to Aegianthus daohugensis, from the Middle Jurassic Daohugou locality, Inner Mongolia, China) is a more interesting case because it preserves more useful characters. Initially it was described as an 'inflorescence' consisting of small 'flowers' with a hexagonal or rarely pentagonal peltate head bearing 'tepals', two different kinds of 'stamens', and small 'carpels 8 '. We have examined specimens of Solaranthus daohugensis from the type locality (Fig. 4) and these specimens show clearly that the socalled carpels are resin bodies that are embedded, isolated from each other, in the tissue of the peltate heads. They are not connected to each other or to the stalk, and although predominantly organized in a radial arrangement they occur at different levels. Similar resin bodies also occur in other parts of the reproductive structures. The peltate heads bear individual long pollen sacs on their margins that contain numerous monocolpate pollen grains.

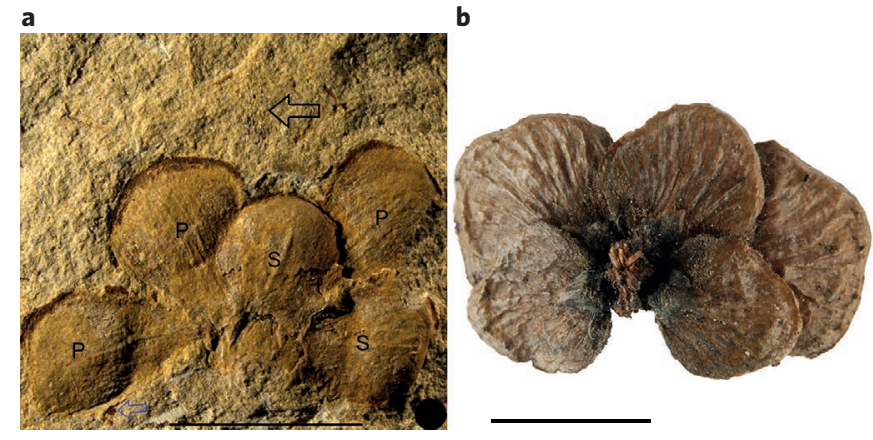

Figure 3 | Euanthus panii and seed cone of modern Tsuga diversifolia for comparison. a, Holotype of Euanthus panii. Arrows and labels are from the original publication. Structures labelled 'S' were interpreted by the authors to be sepals, structures labelled ' $\mathrm{P}$ ' were interpreted to be petals, the black arrow marks a structure interpreted to be a style, and the blue arrow marks a structure interpreted to be a stamen. Reproduced from ref. 78, Taylor \& Francis. b, Fragmentary ovuliferous cone of Tsuga diversifolia collected in the Bergius Botanical Garden, Stockholm, Sweden. Seed cones of some genera of Pinaceae (including Tsuga) readily disintegrate. The cone shown here has lost the distal ovuliferous scales, while the basal scales remain attached to the cone axis. The basalmost ovuliferous scales, corresponding to the 'sepals' of Liu and Wang ${ }^{78}$, are smaller and have a broader base than the successive scales that correspond to the 'petals' of Liu and Wang, which have a narrower base ('claw'). The ovuliferous cone scales are tough with densely spaced bundles, which are also seen in the fragmentary Euanthus fossil, but were not described. The naked cone axis corresponds in shape and size to the structure interpreted by Liu and Wang ${ }^{78}$ as a style. Structures interpreted by the authors as receptacle, ovary and ovule correspond to the minute non-ovuliferous scales and the detachment scar of the cone. Scale bars, $5 \mathrm{~mm}$. Image courtesy of $\mathrm{C}$. Pott.

Fossils similar to Solaranthus daohugensis are known from other Jurassic and Early Cretaceous floras in East Asia, and were transferred by Deng et al. ${ }^{86}$ to the extinct genus Aegianthus ${ }^{87}$. Until further comparative studies are carried out, we accept the taxonomic transfer by Deng et al. ${ }^{86}$ and note that these specimens closely resemble other species of Aegianthus from the Jurassic and Early Cretaceous of East Asia ${ }^{86,87}$.

Aegianthus daohugensis is particularly similar to Aegianthus resinifer, originally described as Loricanthus resinifer ${ }^{88}$ from the Early Cretaceous of Transbaikal. Both species have identical polygonal peltate microsporangiate heads with resin bodies of similar size and distribution, and also produced very similar monocolpate pollen. These features are also seen in Aegianthus hailarensis, but Aegianthus sibericus apparently lacks resin bodies in the peltate heads.

The relationships of Aegianthus are uncertain, but none of these fossils, including the material from Daohugou that we have examined, provide any evidence that supports a relationship to angiosperms. A relationship to cycads was suggested by Deng et al. ${ }^{86}$, while Krassilov and Bugdaeva ${ }^{87,88}$ suggested a relationship with Gnetales sensu lato. We favour the latter interpretation, in part because similar peltate microsporangiate heads are also known for the Erdtmanithecales, which are thought to be closely related to the Gnetales ${ }^{10}$. Tekleva and Krassilov ${ }^{89}$ also demonstrated a thick laminated endexine, unknown among angiosperms, in pollen from $A$. resinifer and noted the ultrastructural resemblance to the erdtmanithecalean pollen genus Eucommiidites.

\section{Prospects for understanding early angiosperm history}

Ever since Darwin highlighted the seemingly sudden appearance of angiosperms in the mid-Cretaceous, the search for angiosperms prior to the Early Cretaceous has been intensive. So far, this search has been unsuccessful. The earliest fossil remains that can 


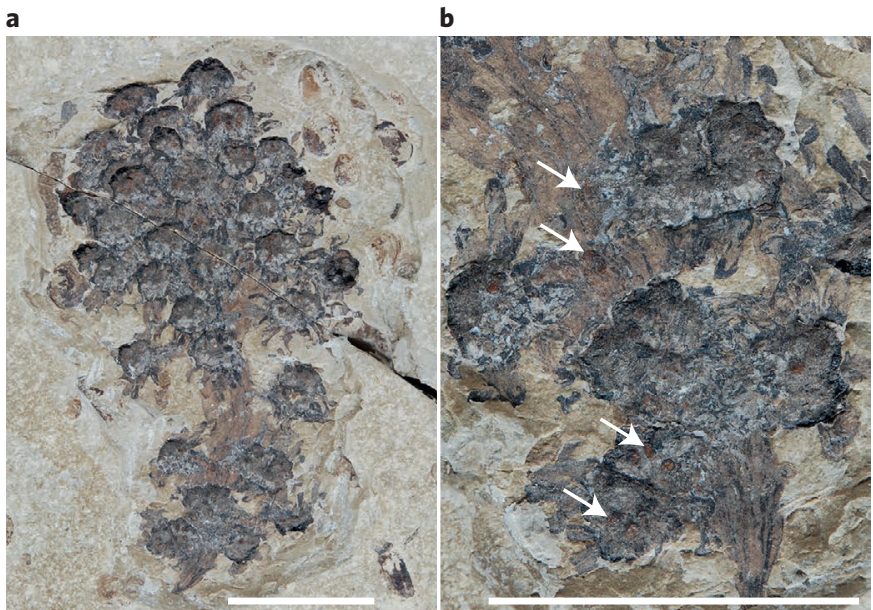

Figure 4 | Solaranthus daohugensis (Aegianthus daohugensis) from the type locality, deposited in the collections of the Institute of Vertebrate Palaeontology and Palaeoanthropology, Beijing, China (specimen number B0252). a, Axis with numerous pollen organs with peltate heads bearing long pollen sacs on their margins, which contain monocolpate pollen grains. b. Close up of pollen organs showing pollen sacs and numerous resin bodies (arrows). Zheng and Wang ${ }^{85}$ interpreted each peltate structure to represent a flower. The structures that they interpreted as carpels are resin bodies, which are present not only in the peltate head but also in the central axis of the structure. Scale bars, $10 \mathrm{~mm}$.

be assigned with very high confidence to crown-group angiosperms are tricolpate pollen grains from the Barremian-Aptian transition ${ }^{5}$. Slightly older (Hauterivian) dispersed pollen provides evidence of crown-group angiosperms, but with lower confidence. From the Aptian and onwards, there are numerous fossil flowers and isolated floral organs as well as leaves reported from both macrofossil and mesofossil floras in the Northern and Southern hemispheres that indicate the presence of crown-group angiosperms with high confidence ${ }^{10,90-93}$. The more or less synchronous diversification of fossil pollen, mesofossils and macrofossils through the Early Cretaceous, in orderly patterns that are consistent with our developing understanding of angiosperm phylogeny, would be difficult to explain if angiosperms had diversified cryptically for a significant period of time in environments unsuitable for fossil preservation ${ }^{4,10}$.

Scattered reports of putative angiosperms from Jurassic and earlier rocks appear to challenge the conclusion made more than 50 years ago, that no unequivocal angiosperm remains have yet been described from rocks older than Early Cretaceous ${ }^{1}$, but so far none of them withstand careful scrutiny. In some cases, fossil material from the Triassic and Jurassic presents interesting features that document extinct diversity among seed plants that may or may not be related to angiosperms, but the absence of critical details, or knowledge of other parts of these parent plants, currently precludes their assignment to angiosperms. In other cases (for example many of the fossils discussed above), interpretations of angiosperm features, generally in very poorly preserved fossil material, are not credible. What is needed is the kind of evidence now available from the Aptian onwards of unequivocal angiosperm stamens and carpels.

The history of palaeobotany suggests that plants on the angiosperm stem-lineage, with some, but not all of the critical features of living angiosperms, will ultimately be recognized in Jurassic or earlier rocks. It is also possible that the pattern of angiosperm appearance and early diversification that has been revealed by two centuries of palaeobotanical research will be overturned by a single discovery of a remarkable pre-Cretaceous fossil with features that allow it to be assigned with high confidence to the angiosperm stem group or crown group. Such a discovery would be welcomed because it would probably be informative about many aspects of early angiosperms that remain poorly understood. It would most likely come from a careful search of well-preserved plant fossil assemblages from the latest Jurassic. So far, however, we have no such fossil. Unsubstantiated assertions as to the angiosperm affinity of pre-Cretaceous fossils undermine more critical palaeobotanical research and potentially create confusion, especially in the context of the pre-Cretaceous ages inferred for angiosperms and certain angiosperm subgroups from some molecular dating studies.

\section{Received 15 November 2016; accepted 24 January 2017;} published 3 March 2017

\section{References}

1. Scott, R. A., Barghoorn, E. S. \& Leopold, E. How old are the angiosperms? Am. J. Sci. 258, 284-299 (1960).

2. Hughes, N. F. Fossil evidence and angiosperm ancestry. Sci. Prog. 49, 84-102 (1961).

3. Muller, J. Palynological evidence on early differentiation of angiosperms. Biol. Rev. 45, 417-450 (1970).

4. Doyle, J. A. \& Hickey, L. J. in Origin and Early Evolution of Angiosperms (ed. Beck, C. B.) 139-206 (Columbia University Press, 1976).

5. Hughes, N. F. The Enigma of Angiosperm Origins (Cambridge University Press, 1994).

6. Soltis, D. E. et al. Angiosperm phylogeny: 17 genes, 640 taxa. Am. J. Bot. 98, 704-730 (2011).

7. Qiu, Y.-L. et al. The earliest angiosperms: evidence from mitochondrial, plastid and nuclear genomes. Nature 402, 404-407 (1999).

8. The Angiosperm Phylogeny Group. An update of the Angiosperm Phylogeny Group classification for the orders and families of flowering plants: APG IV. Bot. J. Linn. Soc. 181, 1-20 (2016).

9. Hughes, N. F. Palaeobiology of Angiosperm Origins (Cambridge University Press, 1976).

10. Friis, E. M., Crane, P. R. \& Pedersen, K. R. Early Flowers and Angiosperm Evolution (Cambridge University Press, 2011).

11. Mohr, B. A. R., Bernardes-de-Oliveira, M. E. C. \& Loveridge, R. F. in The Crato Fossil Beds of Brazil: Window into an Ancient World (eds Martill, D. M. Bechly, G. \& Loveridge, R. F.) 537-565 (Cambridge University Press, 2007).

12. Sun, G. et al. Archaefructaceae, a new basal angiosperm family. Science 296, 899-904 (2002).

13. Leng, Q. \& Friis, E. M. Sinocarpus decussatus gen. et sp. nov., a new angiosperm with syncarpous fruits from the Yixian Formation of Northeast China. Pl. Syst. Evol. 241, 77-88 (2003).

14. Friis, E. M., Pedersen, K. R. \& Crane, P. R. Kenilanthus, a new eudicot flower with tricolpate pollen from the Early Cretaceous (early-middle Albian) of eastern North America. Grana 56, 161-173 (2016).

15. Friis, E. M., Crane, P. R., Pedersen, K. R., Stampanoni, M. \& Marone, F. Exceptional preservation of tiny embryos documents seed dormancy in early angiosperms. Nature 528, 551-554 (2015).

16. Wikström, N., Savolainen, V. \& Chase, M. W. Evolution of the angiosperms. Calibrating the tree. Proc. R. Soc. Lond. B 268, 2211-2220 (2001).

17. Anderson, C. L., Bremer, K. \& Friis, E. M. Dating phylogenetically basal eudicots using $r b c L$ sequences and multiple fossil reference points. Am. J. Bot. 92, 1737-1748 (2005).

18. Magallón, S. \& Castillo, A. Angiosperm diversification through time. Am. J. Bot. 96, 349-365 (2009).

19. Bell, C. D., Soltis, D. E. \& Soltis, P. S. The age and diversification of the angiosperms re-revisited. Am. J. Bot. 97, 1296-1303 (2010).

20. Beaulieu, J. M., O’Meara, B. C., Crane, P. R. \& Donoghue, M. J. Heterogeneous rates of molecular evolution and diversification could explain the Triassic age estimate for angiosperms. Syst. Biol. 64, 869-878 (2015).

21. Smith, S. A., Beaulieu, J. M. \& Donoghue, M. J. An uncorrelated relaxed-clock analysis suggests an earlier origin for flowering plants. Proc. Natl Acad. Sci. USA 107, 5897-5902 (2010).

22. Doyle, J. A. Molecular and fossil evidence on the origin of angiosperms. Ann. Rev. Earth Planet. Sci. 40, 301-326 (2012).

23. Doyle, J. A. Recognising angiosperm clades in the Early Cretaceous fossil record. Hist. Biol. 27, 414-429 (2015).

24. Zeng, L. et al. Resolution of deep angiosperm phylogeny using conserved nuclear genes and estimates of early divergence times. Nat. Commun. 5, 4956 (2014).

25. Doyle, J. A. \& Donoghue, M. J. Phylogenies and angiosperm diversification. Paleobiology 19, 141-167 (1993).

26. Crane, P. R., Friis, E. M. \& Pedersen, K. R. The origin and early diversification of angiosperms. Nature 374, 27-33 (1995) 
27. Judd, W. S., Campbell, C. S., Kellogg, E. A., Stevens, P. F. \& Donoghue, M. J. Plant Systematics: a Phylogenetic Approach 2nd edn (Sinauer Associates, 2002)

28. Rudall, P. J. \& Bateman, R. M. Defining the limits of flowers: the challenge of distinguishing between the evolutionary products of simple versus compound strobili. Phil. Trans. R. Soc. B 365, 397-409 (2010).

29. Friis, E. M., Pedersen, K. R., von Balthazar, M., Grimm, G. W. \& Crane, P. R. Monetianthus mirus gen. et sp. nov., a nymphaealean flower from the Early Cretaceous of Portugal. Int. J. Plant Sci. 170, 1086-1101 (2009).

30. Friis, E. M., Grimm, G. W., Mendes, M. M. \& Pedersen, K. R. Canrightiopsis, a new Early Cretaceous fossil with Clavatipollenites-type pollen bridge the gap between extinct Canrightia and extant Chloranthaceae. Grana 54, 184-212 (2015)

31. Dilcher, D. L. \& Crane, P. R. Archaeanthus: an early angiosperm from the Cenomanian of the Western Interior of North America. Ann. Missouri Bot. Gard. 71,351-383 (1984)

32. Drinnan, A. N., Crane, P. R., Friis, E. M. \& Pedersen, K. R. Lauraceous flowers from the Potomac Group (mid-Cretaceous) of eastern North America. Bot. Gaz 151, 370-384 (1990).

33. Mendes, M. M., Grimm, G. W., Pais, J. \& Friis, E. M. Fossil Kajanthus lusitanicus gen. et sp. nov. from Portugal: floral evidence for Early Cretaceous Lardizabalaceae (Ranunculales, basal eudicot). Grana 53, 283-301 (2014).

34. Friis, E. M., Doyle, J. A., Endress, P. K. \& Leng, Q. Archaefructus - angiosperm precursor or specialized early angiosperm? Trends Plant Sci. 8, 369-373 (2003).

35. Doyle, J. A. \& Endress, P. K. Integrating Early Cretaceous fossils into the phylogeny of living angiosperms: ANITA lines and relatives of Chloranthaceae. Int. J. Plant Sci. 175, 555-600 (2014)

36. Hughes, N. F. \& McDougall, A. B. Search for antecedents of Early Cretaceous monosulcate columellate pollen. Rev. Palaeobot. Palynol. 83, 175-183 (1994).

37. Hughes, N. F. Plant succession in the English Wealden strata. Proc. Geol. Ass. 86, 439-455 (1975).

38. Hughes, N. F., Drewry, G. \& Laing, J. F. Barremian earliest angiosperm pollen. Palaeontology 22, 513-536 (1979).

39. Hughes, N. F. \& McDougall, A. B. Records of angiospermid pollen entry into the English Early Cretaceous succession. Rev. Palaeobot. Palynol. 50, 255-272 (1987).

40. Hughes, N. F., McDougall, A. B. \& Chapman, J. L. Exceptional new record of Cretaceous Hauterivian angiospermid pollen from southern England. J. Micropalaeontol. 10, 75-82 (1991).

41. Brenner, G. J. in Flowering Plant Origin, Evolution and Phylogeny (eds Taylor, D. W. \& Hickey, L. J.) 91-115 (Chapman \& Hall, 1996).

42. Crane, P. R., Doyle, J. A., Donoghue, M. J. \& Friis, E. M. Angiosperm origins. Nature 342, 131 (1989).

43. Ibrahim, M. I. A., Zobaa, M. K., El-Noamani, Z. M. \& Tahoun, S. S. A review of the angiosperm pollen genus Cretacaeiporites Herngreen, with one new species from the Upper Cretaceous of Egypt. Palynology 41, 101-116 (2015).

44. Hughes, N. F. \& McDougall, A. B. Barremian-Aptian angiospermid pollen records from southern England. Rev. Palaeobot. Palynol. 65, 145-151 (1990).

45. Walker, J. W. \& Walker, A. G. Ultrastructure of Lower Cretaceous angiosperm pollen and the origin and early evolution of flowering plants. Ann. Missouri Bot. Gard. 71, 464-521 (1984).

46. Lidgard, S. \& Crane, P. R. Angiosperm diversification and Cretaceous floristic trends: a comparison of palynofloras and leaf macrofloras. Paleobiology 16, 77-93 (1990).

47. Cornet, B. Late Triassic angiosperm-like pollen from the Richmond Rift Basin of Virginia, U.S.A. Palaeontogr. Abt. B 213, 37-87 (1989).

48. Hochuli, P. A. \& Feist-Burkhardt, S. Angiosperm-like pollen and Afropollis from the Middle Triassic (Anisian) of the Germanic Basin (Northern Switzerland). Front. Plant Sci. 4, 344 (2013).

49. Hochuli, P. A. \& Feist-Burkhardt, S. A boreal early cradle of angiosperms? Angiosperm-like pollen from the Middle Triassic of the Barents Sea (Norway). J. Micropalaeontol. 23, 97-104 (2004).

50. Doyle, J. A. \& Hotton, C. L. in Pollen and Spores, Patterns of Diversity Systematics Association Special Volume 44 (eds Blackmore, S. \& Barnes, S. H.) 169-195 (Clarendon Press, 1991).

51. Friis, E. M. \& Pedersen, K. R. Eucommiitheca, a new pollen organ with Eucommiidites pollen from the Early Cretaceous of Portugal. Grana 35, 104-112 (1996)

52. Couper, R. A. Evidence for a possible gymnospermous affinity for Tricolpites troedssonii Erdtman. New Phytol. 55, 280-285 (1956).

53. Reymanówna, M. On seeds containing Eucommiidites troedssonii pollen from the Jurassic of Grojec, Poland. Bot. J. Linn. Soc. 61, 147-152 (1968).

54. Brenner, G. J. The gymnospermous affinity of Eucommiidites Erdtman, 1948 Rev. Palaeobot. Palynol. 5, 123-127 (1967).

55. Pedersen, K. R., Crane, P. R. \& Friis, E. M. Pollen organs and seeds with Eucommiidites pollen. Grana 28, 279-294 (1989).

56. Mendes, M. M., Pais, J., Pedersen, K. R. \& Friis, E. M. Erdtmanitheca portucalensis, a new pollen organ from the Early Cretaceous (Aptian-Albian) of Portugal with Eucommiidites-type pollen. Grana 49, 26-36 (2010).
57. Gordenko, N. V. Vladimariales ordo nov. (Gymnospermae) from the Middle Jurassic deposits of the Mikhailovskii Rudnik locality (Kursk Region, European Russia). Paleontol. J. 44, 1281-1307 (2010).

58. Shi, G. et al. Early Cretaceous Umkomasia from Mongolia: implications for homology of corystosperm cupules. New Phytol. 210, 1418-1429 (2016).

59. Pedersen, K. R. \& Friis, E. M. Caytonanthus pollen from the Lower and Middle Jurassic. GeoSkrifter 24, 255-267 (1986).

60. Friis, E. M., Pedersen, K. R. \& Crane, P. R. Angiosperm floral structures from the Early Cretaceous of Portugal. Plant Syst. Evol. 8, 31-49 (1994).

61. Friis, E. M., Pedersen, K. R. \& Crane, P. R. New diversity among Chlamydospermous seeds from the Early Cretaceous of Portugal and North America. Int. J. Plant Sci. 174, 530-558 (2013).

62. Friis, E. M. et al. Phase contrast enhanced synchrotron-radiation X-ray analyses of Cretaceous seeds link Gnetales to extinct Bennettitales. Nature 450, 549-552 (2007).

63. Friis, E. M., Pedersen, K. R. \& Crane, P. R. Early Cretaceous mesofossils from Portugal and eastern North America related to the BennettitalesErdtmanithecales-Gnetales group. Am. J. Bot. 96, 252-283 (2009).

64. Friis, E. M., Pedersen, K. R. \& Crane, P. R. Welwitschioid diversity in the Early Cretaceous: evidence from fossil seeds with pollen from Portugal and eastern North America. Grana 53, 175-196 (2014).

65. Hill, C. R. A plant with flower-like organs from the Wealden of the Weald (Lower Cretaceous), southern England. Cretaceous Res. 17, 27-38 (1996).

66. Gomez, B., Daviero-Gomez, V., Coiffard, C., Martín-Closas, C. \& Dilcher, D. L. Montsechia, an ancient aquatic angiosperm. Proc. Natl Acad. Sci. USA 112, 10985-10988 (2015)

67. Wang, X. \& Han, G. The earliest ascidiate carpel and its implications for angiosperm evolution. Acta Geol. Sinica 85, 998-1112 (2011).

68. Li, H. Early Cretaceous sarraceniacean-like pitcher plants from China. Acta Bot. Gallica 152, 227-234 (2005).

69. Wong, W. O., Dilcher, D. L., Labandeira, C. C., Sun, G. \& Fleischmann, A. Early Cretaceous Archaeamphora is not a carnivorous angiosperm. Front. Plant Sci. https://doi.org/10.3389/fpls.2015.00326 (2015).

70. Han, G., Fu, X.-P., Liu, Z.-J. \& Wang, X. A new angiosperm genus from the Lower Cretaceous Yixian Formation, western Liaoning, China. Acta Geol. Sinica 87, 916-925 (2013).

71. Wang, X. \& Zheng, S. The earliest normal flower from Liaoning Province, China. J. Integr. Plant Biol. 51, 800-811 (2009).

72. Duan, $\mathrm{S}$. The oldest angiosperm - a tricarpous female reproductive fossil from western Liaoning Province, NE China. Sci. China Ser. D-Earth Sci. 41, 14-20 (1998).

73. Yang, Y. A systematic classification of Ephedraceae: living and fossil. Phytotaxa 158, 283-290 (2014)

74. Yang, Y. \& Ferguson, D. K. Macrofossil evidence unveiling evolution and ecology of early Ephedraceae. Perspect. Plant Ecol. Evol. Syst. 17, 331-346 (2015)

75. Krassilov, V. A. Early Cretaceous flora of Mongolia. Palaeontogr. Abt. B 181, 1-43 (1982).

76. Sun, G., Dilcher, D. L., Zheng, S. \& Zhou, Z. In search of the first flower: a Jurassic angiosperm, Archaefructus, from northeast China. Science 282, 1692-1695 (1998).

77. Crane, P. R. Review of Cornet, B., The leaf venation and reproductive structures of a Late Triassic angiosperm, Sanmiguelia lewisii. Taxon 36, 778-779 (1987)

78. Liu, Z.-J. \& Wang, X. A perfect flower from the Jurassic of China. Hist. Biol. 28, 707-719 (2015)

79. Han, G. et al. A whole plant herbaceous angiosperm from the Middle Jurassic of China. Acta Geol. Sinica 90, 19-29 (2016).

80. Liu, Z.-J. \& Wang, X. Yuhania: a unique angiosperm from the Middle Jurassic of Inner Mongolia, China. Hist. Biol. http://dx.doi.org/10.1080/08912963.2016. 1178740 (2016)

81. Wang, X. \& Wang, S.-J. Xingxueanthus: an enigmatic Jurassic seed plant and its implications for the origin of angiospermy. Acta Geol. Sinica 84, 47-55 (2010).

82. Wang, X., Duan, S., Geng, B., Cui, J. \& Yang, Y. Schmeissneria: a missing link to angiosperms? BMC Evol. Biol. 7, 14 (2007).

83. Wang, X. Schmeissneria: an angiosperm from the Early Jurassic. J. Syst. Evol. 48, 326-335 (2010).

84. van Konijnenburg-van Cittert, J. H. A. The Early Jurassic male ginkgoalean inflorescence Stachyopitys preslii Schenk and its in situ pollen. Scr. Geol. Special Issue 7, 141-149 (2010).

85. Zheng, S. \& Wang, X. An undercover angiosperm from the Jurassic of China Acta Geol. Sinica 84, 895-902 (2010).

86. Deng, S., Hilton, J., Glasspool, I. J. \& Dejax, J. Pollen cones and associated leaves from the Lower Cretaceous of China and a re-evaluation of Mesozoic male cycad cones. J. Syst. Palaeontol. 12, 1001-1023 (2014).

87. Krassilov, V. A. \& Bugdaeva, E. V. Gnetalean plants from the Jurassic of Ust-Balej, East Siberia. Rev. Palaeobot. Palynol. 53, 359-374 (1988). 
88. Krassilov, V. A. \& Bugdaeva, E. V. An angiosperm cradle community and new proangiosperm taxa. Acta Palaeobot. Suppl. 2, 111-127 (1999).

89. Tekleva, M. V. \& Krassilov, V. A. Comparative pollen morphology and ultrastructure of modern and fossil gnetophytes. Rev. Palaeobot. Palynol. 156, 130-138 (2009).

90. Mohr, B. A. R. \& Bernardes-de-Oliveira, M. E. C. Endressinia brasiliana, a Magnolialean Angiosperm from the Lower Cretaceous Crato Formation (Brazil). Int. J. Plant Sci. 165, 1121-1133 (2004).

91. Mohr, B. A. R., Bernardes-de-Oliveira, M. E. C. \& Taylor, D. W. Pluricarpellatia, a nymphaealean angiosperm from the Lower Cretaceous of northern Gondwana (Crato Formation, Brazil). Taxon 57, 1147-1158 (2008).

92. Cantrill, D. J. \& Nichols, G. J. Taxonomy and palaeoecology of Early Cretaceous (Late Albian) angiosperm leaves from Alexander Island, Antarctica. Rev. Palaeobot. Palynol. 92, 1-28 (1996).

93. Upchurch, G. R. Cuticle evolution in Early Cretaceous angiosperms from the Potomac Group of Virginia and Maryland. Ann. Missouri Bot. Gard. 71, 522-550 (1984).

\section{Acknowledgements}

We thank the Institute of Vertebrate Paleontology and Paleoanthropology in

Beijing, China for loaning the specimen of Solaranthus daohugensis and C. Pott for photographing this specimen and the Tsuga cone. We thank P. von Knorring for creating Figs 1 and 2. We thank J. Doyle and two anonymous reviewers for constructive comments on the manuscript. This work was funded in part by NSF grant DEB1348456 to P.S.H. and P.R.C. and the Swedish Research Council grant 2014-5228 to E.M.F.

\section{Author contributions}

All authors contributed to the design and scope of the paper, and evaluations of the fossil taxa discussed in the paper. All authors contributed to writing and revising the manuscript.

\section{Additional information}

Reprints and permissions information is available at www.nature.com/reprints. Correspondence should be addressed to P.S.H.

How to cite this article: Herendeen, P. S., Friis, E. M., Pedersen, K. R. \& Crane, P. R. Palaeobotanical redux: revisiting the age of the angiosperms. Nat. Plants 3, 17015 (2017).

\section{Competing interests}

The authors declare no competing financial interests. 